\title{
On the Mechanism of Sodic Removal \\ from Bauxite Residue and Bauxite Desilication Products (BDP) Using Microbiogenic Acids
}

\author{
SICHENG WANG, TUAN NGUYEN, HONG PENG, FANG \\ YOU AND LONGBIN HUANG
}

The University of Queensland

Presenting Author: sicheng.wang@uq.edu.au

Bauxite desilication products (BDP) are fundamental causes of persistent alkalinity and salinity in bauxite residue (BR). Previous studies have shown that significant amounts of microbiogenic acids (e.g., $\mathrm{CH}_{3} \mathrm{COOH}, \mathrm{H}_{2} \mathrm{C}_{2} \mathrm{O}_{4}$ ) and $\mathrm{Na}^{+}$were detected in the pore water of organic matter-amended and bacteria-colonised bauxite residue, implying the capability of microbiogenic acids to alleviate the alkalinity and salinity of bauxite residue [1]. The present study aims to establish a fundamental understanding of bauxite residue/BDP weathering mechanism by using microbiogenic acids as case models of microbial-derived low-molecular-weight soluble organic compounds. The sodium concentration in microbiogenic acidstreated bauxite residues has significantly decreased in the mineral phase, which is dominated by $\mathrm{Na}^{+}-\mathrm{H}^{+}$exchange process with partial breakdown of aluminosilicate $\beta$-cages. According to the results from Attenuated total reflection and fourier-transform infrared spectroscopy (ATR-FTIR), Raman spectroscopy, nuclear magnetic resonance (NMR) spectroscopy, and X-Ray photoelectron spectra, it was indicated that acetate and oxalate were adsorbed/complexed on the surface of BDP, causing slight deformation of BDP's cages and thus enhancing surficially encaged $\mathrm{Na}^{+}$easily detached from alkaline mineral surface [1-3]. The atomistic molecular dynamic simulation confirmed the adsorption of the microbiogenic acid molecules on the cleaved (110) surface of hydroxylsodalite, through either interactions with $\mathrm{Al}$ or $\mathrm{Si}$ atoms of the $\beta$-cages or hydrogen bonding with surface oxygen atoms. In addition to critical $\mathrm{Na}^{+}-\mathrm{H}^{+}$exchange process, the adsorption of microbiogenic acids on BDP also contribute to triggering surfacial $\mathrm{Na}^{+}$diffusion into aqueous solution from hydroxylsodalite $b$-cages. These collectively suggested that the continuous $\mathrm{Na}^{+}-\mathrm{H}^{+}$(organic) exchange process mediated by the organic acid complexation would be critical to the depletion of BDP and dealkalization of the treated bauxite residue in the long-term, preventing future release of $\mathrm{Na}$ into the soluble phase and the reversal of the alkalinity. These findings may lead to unlocking the barriers to sustainable bauxite residue rehabilitation.

[1] You, F., et al. (2019) Sci Total Environ 663, 216-226.

[2] Wang, S., et al. (2020) JOM 72, 309-318.

[3] Huang, L. et al. (2018) Alumina Conference, Australia. 